\title{
Acid-Alkaline Treatment of Mordenite and Its Catalytic Activity in the Hydrotreatment of Bio-Oil
}

\author{
Febi Yusniyanti ${ }^{1}$, Wega Trisunaryanti ${ }^{2}$, and Triyono ${ }^{2, *}$ \\ ${ }^{1}$ Department of Chemistry, Islamic State University Maulana Malik Ibrahim, \\ Jl. Gajayana No. 50, Dinoyo, Lowokawaru, Malang 65144, Indonesia \\ ${ }^{2}$ Department of Chemistry, Faculty of Mathematics and Natural Sciences, Universitas Gadjah Mada, \\ Sekip Utara, Yogyakarta 55281, Indonesia
}

${ }^{*}$ Corresponding author:

tel: $+62-8157950957$

email: triyn102@ugm.ac.id

Received: November 14, 2019

Accepted: May 4, 2020

DOI: $10.22146 / \mathrm{ijc} .51496$

\begin{abstract}
Acid-alkaline treatment using acetic acid and sodium hydroxide (NaOH) were applied on mordenite (MOR) to increase the Si/Al ratio and surface area properties. Various time treatment $(3,6$, and $9 \mathrm{~h})$ and concentration of acetic acid (6, 9, and $12 \mathrm{M})$ were used to treat $\mathrm{MOR}$, and followed by the treatment with $\mathrm{NaOH}(0.1 \mathrm{M})$ under room temperature. The MOR and treated mordenite were applied as a catalyst for hydrotreatment of cellulose-derived bio-oil. The acetic acid treatment caused the increase of the Si/Al ratio of mordenite up to 27.03. The Si/Al ratio was determined using ICPAES analysis which was also confirmed using FT-IR analysis. The acidity was determined using $\mathrm{NH}_{3}$ vapors adsorption. The acidity test revealed that as the Si/Al ratio increased the acidity of mordenite decreased. The advantage of using acetic acid for acid treatment was that the XRD patterns of mordenite can be preserved with a little decrease of the intensity. On the other hand, the $\mathrm{NaOH}$ treatment under room temperature decreased the crystallinity down to $68 \%$, which was calculated using XRD. The acid-alkaline treatment of mordenite succeeded to increase the surface area 2 times larger than the parent mordenite. The surface area was obtained from BET analysis. The acid-alkaline treated mordenite exhibited better catalytic activity upon hydrotreatment of biomassderived bio-oil compared to the parent mordenite which corresponded to its highest surface area.
\end{abstract}

Keywords: acetic acid; bio-oil; dealumination; hydrotreatment; mordenite

\section{- INTRODUCTION}

Mordenite is a microporous aluminosilicate crystalline which belong to a large-pore zeolite family [1$2]$. It consists of a 12-membered ring (MR) pore channels of $0.67 \times 0.70 \mathrm{~nm}$, interconnected by 8 -MR pores of 0.34 $\times 0.48 \mathrm{~nm}$ [3-4]. Mordenite is one of the zeolites that can be employed as a catalyst in industrial processes such as alkylation and hydroisomerization [1,5-6]. The wide range application of mordenite is due to the mechanic and thermal stability of the mordenite structure [1]. High surface area, high Brønsted acidity, and flexible framework are unique properties of mordenite that also contributes to its extensive use [2,7-8]. Despite the immense use of mordenite as a catalyst, there are some drawback of mordenite. Mordenite has high aluminum content causing it to be undesired to be used as a catalyst. Aluminum can easily leach in the presence of water and acid which affects the chemical stability of mordenite as a catalyst [9-10]. In addition, it is reported that mordenite undergoes rapid deactivation due to the limited mass transfer between product and reactant $[3,8]$.

Several ways to overcome the disadvantages of mordenite has been reported by many researchers. The most sought after method is post-synthesis treatment using acid and alkaline solution [11-12]. The acid and alkaline treatment can enhance the mordenite properties by magnifying mass transfer and catalytic 
activity [12-15]. Strong acid treatment affects the structure of mordenite. It is reported that employing strong acid on mordenite causes a partial loss in mordenite structure $[8,13]$. On the other hand, employing weak acids such as oxalic acid and acetic acid can preserve the structure of mordenite $[4,8]$. Throughout the acid treatment, the aluminum atoms are removed from the mordenite framework and extra-framework aluminum (EFAl) are formed [16]. The EFAl contributes to the addition of acid sites on the mordenite surface which increase the catalytic activity [16]. The utilization of strong acid and oxalic acid can completely remove the EFAl during the acid treatment, hence these acids are undesired to be used in treatment of mordenite.

Alkaline treatment is another way to increase zeolite properties such as mordenite. This treatment is mostly done using sodium hydroxide $(\mathrm{NaOH})$. A low concentration of $\mathrm{NaOH}(0.1-0.5 \mathrm{M})$ can be used for alkaline treatment and can maintain the crystallinity of zeolite [17]. Alkaline treatment is mostly done at high temperature, however it can cause severe decrease in the crystallinity of zeolite. Interestingly, strong acid sites were formed during the alkaline treatment and the treated zeolite exhibited better catalytic activity than the parent zeolite [18]. A recent report on the low temperature of alkaline treatment caught attention of many researchers. This process removed the Si atom up to $78 \%$ from zeolite structure [19]. However, this caused the amorphization of zeolite. Therefore, controlling the concentration of $\mathrm{NaOH}$ is important to sustain mordenite structure.

In this work, mordenite was treated using acetic acid and $\mathrm{NaOH}$. Various concentrations and condition time of acetic acid treatment were performed to obtain the effective condition to remove the $\mathrm{Al}$ atom from mordenite. The treated mordenite was used as a catalyst in the hydrotreatment of bio-oil to investigate its catalytic activity.

\section{- EXPERIMENTAL SECTION}

\section{Materials}

Ca-Mordenite (HSZ-642NAA) was purchased from Tosoh Co. Glacial acetic acid $\left(\mathrm{CH}_{3} \mathrm{COOH}\right)$, sodium hydroxide $(\mathrm{NaOH})$, ammonium chloride $\left(\mathrm{NH}_{4} \mathrm{Cl}\right)$, silver nitrate $\left(\mathrm{AgNO}_{3}\right)$, nitric acid $65 \%\left(\mathrm{HNO}_{3}\right)$, hydrochloric acid $37 \%(\mathrm{HCl})$, hydrofluoric acid $40 \%(\mathrm{HF})$ and ammonia solution $25 \%\left(\mathrm{NH}_{3}\right)$ were purchased from Merck. All chemicals were of analytical grade. $\mathrm{N}_{2}$ gas and $\mathrm{H}_{2}$ gas were purchased from Samator Ltd., and distilled water was used during the experiments.

\section{Instrumentation}

Inductively coupled plasma-atomic emission spectrometer (ICP-AES) Shimadzu model ICPE-9820, Fourier transform-infrared (FTIR) spectrophotometer Thermo Nicolet iS10, X-Ray Diffractometer (XRD) Rigaku Miniflex 600, Gas Sorption Analyzer Quantachrome Touchwin Series, Gas ChromatographyMass Spectroscopy (GC-MS) Shimadzu QP2010S, and other supporting instrumentations, were used in this research.

\section{Procedure}

\section{Preparation of H-mordenite}

Ca-mordenite (denoted as MOR) was calcined at a temperature of $550^{\circ} \mathrm{C}$ for $5 \mathrm{~h}$. Afterwards, the Ca-MOR was introduced into $1 \mathrm{M}$ of $\mathrm{NH}_{4} \mathrm{Cl}$ solution accompanied by stirring at $70-75^{\circ} \mathrm{C}$ for $2 \mathrm{~h}$. The mixture was then filtered and the solid phase was washed until there was no chloride ion in the liquid phase which was confirmed using $\mathrm{AgNO}_{3}$ solution. The solid phase was then dried at $100^{\circ} \mathrm{C}$ and calcined at $550{ }^{\circ} \mathrm{C}$ for $5 \mathrm{~h}$. The obtained solid from this process was named $\mathrm{H}$ mordenite (denoted as HMOR).

\section{Acid-alkaline treatment of HMOR}

This procedure followed the procedures done by Chung [8] and Yusniyanti [9]. H-MOR was treated using $6 \mathrm{M}$ of $\mathrm{CH}_{3} \mathrm{COOH}$ solution ( $1 \mathrm{~g}$ of HMOR in $30 \mathrm{~mL}$ of $\mathrm{CH}_{3} \mathrm{COOH}$ solution) for 3,6 and $9 \mathrm{~h}$ at $90-95^{\circ} \mathrm{C}$. The solid phase was then filtered, washed and dried. Afterwards, the solid material was subsequently calcined at $550{ }^{\circ} \mathrm{C}$ for $5 \mathrm{~h}$ (with a temperature rate of $10^{\circ} \mathrm{C} \mathrm{min}^{-1}$ ) to produce acid treated mordenite. The solids obtained from this step were denoted as $\operatorname{HMOR}(6-\mathrm{x})$, in which $\mathrm{x}$ stood for reflux time variation. In addition, the optimum concentration of $\mathrm{CH}_{3} \mathrm{COOH}$ solution was also investigated using the same procedures under $9 \mathrm{~h}$ of 
reflux. The concentrations of $\mathrm{CH}_{3} \mathrm{COOH}$ solution used in this step were 6,9 and $12 \mathrm{M}$. The solids obtained from this step were denoted as $\operatorname{HMOR}(\mathrm{y}-9)$, in which y stood for acid concentration variation.

The acid treatment of mordenite was then followed by alkaline treatment. The acid-treated mordenite was added into $0.1 \mathrm{M}$ of $\mathrm{NaOH}$ solution for $30 \mathrm{~min}$ at room temperature under constant stirring. Afterwards, the mixture was filtered, dried at $100{ }^{\circ} \mathrm{C}$ for $3 \mathrm{~h}$ and later refluxed using $1 \mathrm{M}$ of $\mathrm{NH}_{4} \mathrm{Cl}$. The solid obtained was calcined at $550{ }^{\circ} \mathrm{C}$ for $5 \mathrm{~h}$ and denoted as $\operatorname{DHMOR}(\mathrm{y}-\mathrm{x})$.

All the samples were destructed using concentrated $\mathrm{HNO}_{3}, \mathrm{HCl}$ and HF. Afterwards, the samples were characterized using ICP-AES to measure the $\mathrm{Si} / \mathrm{Al}$ ratio. Further analysis is needed to confirm the effect of acidalkaline treatment. The samples were characterized using XRD to determine the change of the structure and the crystallinity of the mordenites. The crystallinity of the samples was measured using Eq. (1). HMOR, HMOR(69) and DHMOR(6-9) was further investigated to determine the surface area using a Gas Sorption Analyzer which is also well known as the $\mathrm{N}_{2}$ adsorption-desorption.

$$
\% \text { Crystallinity }=\frac{\text { Area under } 2 \theta: 5-40^{\circ} \text { of Samples }}{\text { Area under } 2 \theta: 5-40^{\circ} \text { of MOR }} \times 100 \%
$$

\section{Catalytic activity test on the hydrotreatment of bio- oil}

The bio-oil used in this research was produced from the pyrolysis of $\alpha$-cellulose. The pyrolysis of $\alpha$-cellulose was done in a semi-batch reactor at temperature of $600{ }^{\circ} \mathrm{C}$ under $\mathrm{N}_{2}$ gas flow (flow rate was $20 \mathrm{~mL} \mathrm{~min}^{-1}$ ) for $2 \mathrm{~h}$. The liquid obtained from this process was characterized by GC-MS to determine its composition. The hydrotreatment of bio-oil was done to improve the biooil properties. The process was carried out in a semi-batch reactor under $\mathrm{H}_{2}$ gas flow (flow rate was $20 \mathrm{~mL} \mathrm{~min}^{-1}$ ) for $2 \mathrm{~h}$ at temperature of $450^{\circ} \mathrm{C}$ in the presence of a catalyst. The catalysts used in this process were HMOR, HMOR(69), and DHMOR(6-9). The weight ratio between catalyst and bio-oil as the feed was 1:30. The thermal treatment of bio-oil was also done in the same condition without a catalyst. The liquid produced from the hydrotreatment and thermal treatment processes was characterized by GC-MS.

\section{Acidity test}

The acidity of the samples were tested by the gravimetric method using adsorption of ammonia vapor. In porcelain crucible, $0.002 \mathrm{~g}$ of the sample was added and placed in a desiccator. The weight of the porcelain crucible before and after the addition of the samples were measured. The desiccator was vacuumed and $\mathrm{NH}_{3}$ vapor was flowed into the desiccator for $30 \mathrm{~min}$ by heating the $25 \%$ ammonia solution until bubbles were formed. Afterwards, the samples were settled for $24 \mathrm{~h}$ in the desiccator. After $24 \mathrm{~h}$, the samples were taken out from the desiccator and the weight of the porcelain crucible with the sample after ammonia adsorption was measured. The acidity of the samples were calculated using Eq. (2).

$\operatorname{Acidity}(\mathrm{mmol} / \mathrm{g})=\frac{\mathrm{W}_{2}-\mathrm{W}_{1}}{\left(\mathrm{~W}_{1}-\mathrm{W}_{0}\right) \times \mathrm{MW}} \times 1000$

where, $\mathrm{W}_{0}$ : the weight of the empty porcelain crucible (g); $W_{1}$ : the weight of the porcelain crucible + sample before adsorption $(\mathrm{g}) ; \mathrm{W}_{2}$ : the weight of the porcelain crucible + sample after adsorption (g); MW: molecular weight of $\mathrm{NH}_{3}(\mathrm{mmol} / \mathrm{g})$

\section{- RESULTS AND DISCUSSION}

\section{Characterization of the Acid-Alkaline Treated Mordenite}

\section{Acid-treated mordenite}

In the acid treatment of zeolite, the acid removes aluminum atoms from the zeolite framework causing an increase in the $\mathrm{Si} / \mathrm{Al}$ ratio of the zeolite. This process is well known as the dealumination process. This process hydrolyzes $\mathrm{Si}-\mathrm{O}-\mathrm{Al}$ bonds, resulting in $-\mathrm{Si}-\mathrm{OH}$ and $-\mathrm{Al}-\mathrm{OH}$, and initiates the formation of vacant sites in the zeolite framework [7]. It is reported that mordenites with $\mathrm{Si} / \mathrm{Al}$ ratio between 25 and 50 exhibit higher stability than mordenites with $\mathrm{Si} / \mathrm{Al}$ ratio below that range (25-50) [3]. Moreover, this $\mathrm{Si} / \mathrm{Al}$ ratio range is also needed to carry out effective silicon removal in alkaline treatment [15].

Since the use of acetic acid is rarely reported for acid treatment of mordenite, it is necessary to evaluate the optimum time and acetic acid concentration required for the treatment. The Si/Al ratios of the 
mordenites are listed in Table 1 . The highest $\mathrm{Si} / \mathrm{Al}$ ratio was obtained using $6 \mathrm{M}$ of acetic acid for $9 \mathrm{~h}$ of treatment. This condition is required to effectively remove silicon from mordenite. The change in $\mathrm{Si} / \mathrm{Al}$ ratio can also be proven using FT-IR characteristics. When the Si/Al ratio increases, the $\mathrm{T}-\mathrm{O}-\mathrm{T}$ band $(\mathrm{T}=\mathrm{Si}$ or $\mathrm{Al})$ tends to shift to a higher wavenumber. This is due to the difference in bond strength between $\mathrm{Al}-\mathrm{O}$ and $\mathrm{Si}-\mathrm{O}$.

The infrared spectra of acid-treated mordenite are depicted in Fig. 1(a) and (b). The band assigned to the $\mathrm{T}-\mathrm{O}$ asymmetric stretching shifted to higher wavenumbers of $1075,1088,1087$ and $1089 \mathrm{~cm}^{-1}$ for

Table 1. The Si/Al ratio of acid-alkaline treated mordenite

\begin{tabular}{lcccc}
\hline Sample & $\begin{array}{c}\text { Conc. Si } \\
(\mathrm{mmol} / \mathrm{L})\end{array}$ & $\begin{array}{c}\text { Conc. Al } \\
(\mathrm{mmol} / \mathrm{L})\end{array}$ & Si/Al Ratio & $\begin{array}{c}\text { Acidity } \\
(\mathrm{mmol} / \mathrm{g})\end{array}$ \\
\hline HMOR & 1.31 & 0.21 & 11.33 & 25.88 \\
HMOR(6-3) & 3.30 & 0.25 & 13.02 & 20.01 \\
HMOR(6-6) & 1.94 & 0.11 & 17.87 & 14.17 \\
HMOR(6-9) & 2.88 & 0.11 & 27.05 & 16.59 \\
HMOR(9-9) & 1.49 & 0.08 & 19.08 & 17.65 \\
HMOR(12-9) & 1.58 & 0.08 & 18.58 & 10.94 \\
DHMOR(6-9) & 1.48 & 0.07 & 21.65 & 12.03 \\
DHMOR(9-9) & 1.47 & 0.08 & 18.94 & 10.87 \\
DHMOR(12-9) & 1.38 & 0.07 & 20.37 & 9.25 \\
\hline
\end{tabular}
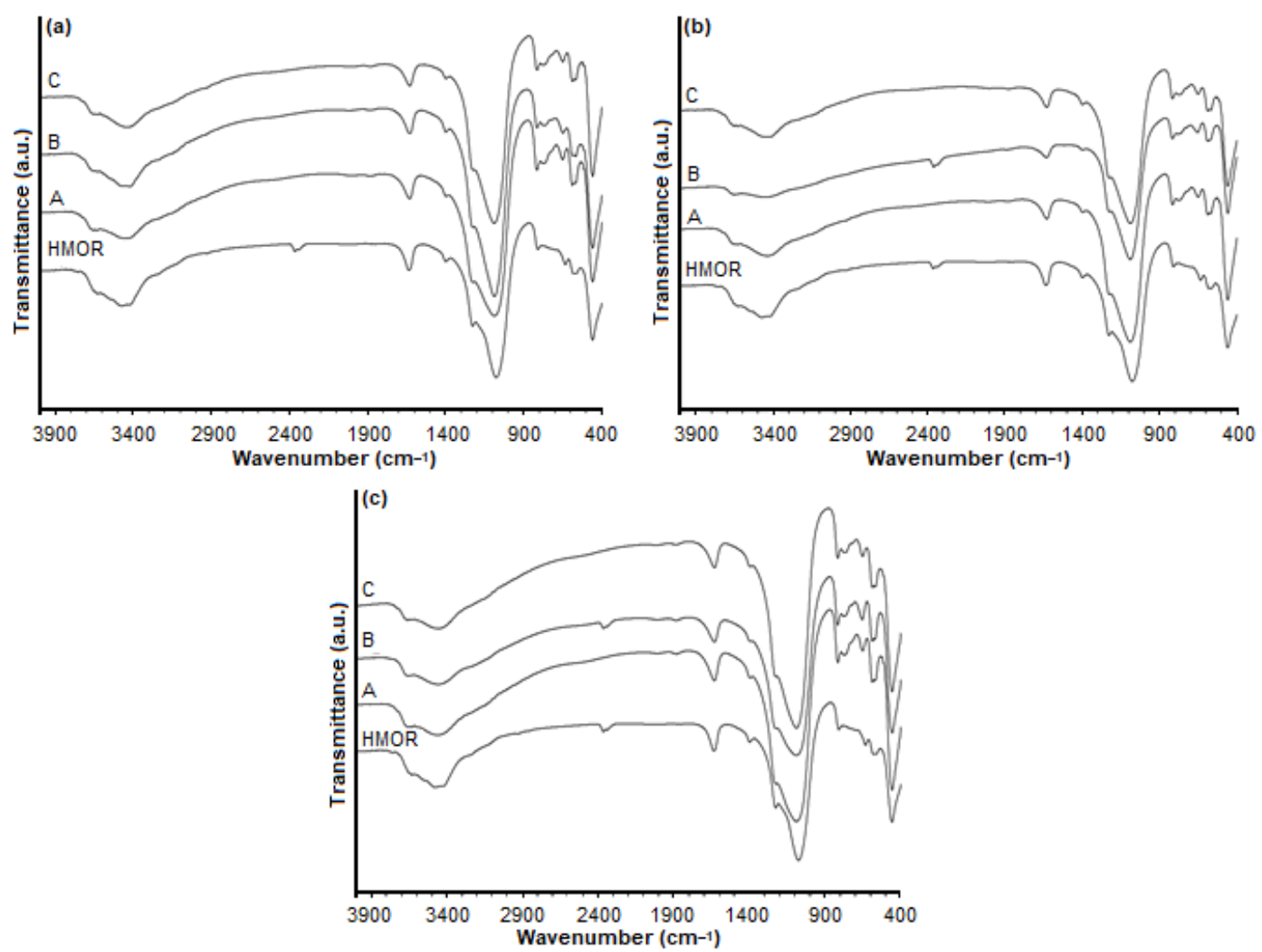

Fig 1. Infrared spectra treated mordenite (a) Treated mordenite using acetic acid $6 \mathrm{M}$ in various treatment time (A. HMOR(6-3), B. HMOR(6-6) and C. HMOR(6-9)), (b) Treated mordenite using the various concentration of acetic acid in 9 h, (A. HMOR(6-9), B. HMOR(9-9 and C. HMOR(9-12)) and (c) Acid-alkaline treated mordenite for various acetic acid concentration (A. DHMOR(6-9), B. DHMOR(9-9) and C. DHMOR(12-9)) 
Table 2. Interpretation of infrared spectra of mordenites

\begin{tabular}{lrrrrrrrrr}
\hline & \multicolumn{1}{c}{ Wavenumber $\left(\mathrm{cm}^{-1}\right)$} \\
\cline { 2 - 9 } Type of vibration & HMOR & $\begin{array}{c}\text { HMOR } \\
(6-3)\end{array}$ & $\begin{array}{r}\text { HMOR } \\
(6-6)\end{array}$ & $\begin{array}{r}\text { HMOR } \\
(6-9)\end{array}$ & $\begin{array}{c}\text { HMOR } \\
(9-9)\end{array}$ & $\begin{array}{c}\text { HMOR } \\
(12-9)\end{array}$ & $\begin{array}{c}\text { DHMOR } \\
(6-9)\end{array}$ & $\begin{array}{c}\text { DHMOR } \\
(9-9)\end{array}$ & $\begin{array}{c}\text { DHMOR } \\
(12-9)\end{array}$ \\
\hline T-O bending & 458 & 457 & 457 & 457 & 482 & 457 & 457 & 457 & 457 \\
T-O Sym. stretching & 632 & 650 & 648 & 649 & 649 & 649 & 652 & 652 & 651 \\
T-O Asym. stretching & 1075 & 1088 & 1087 & 1089 & 1089 & 1088 & 1089 & 1089 & 1090 \\
O-H bending & 1635 & 1630 & 1628 & 1629 & 1630 & 1628 & 1631 & 1631 & 1630 \\
O-H stretching & 3474 & 3454 & 3421 & 3437 & 3453 & 3426 & 3455 & 3453 & 3453 \\
EFAl & 3650 & 3654 & 3653 & 3654 & 3654 & 3654 & 3654 & 3655 & 3655 \\
\hline
\end{tabular}

HMOR, $\operatorname{HMOR}(6-3), \operatorname{HMOR}(6-6)$ and $\operatorname{HMOR}(6-9)$ respectively (Table 2 ). This result is in good agreement with Sandoval-Díaz and co-workers [20].

Throughout the acid treatment, the EFAl can be formed as the result of incomplete removal of $\mathrm{Al}$ atom [16]. The EFAl on the mordenite framework can be detected in FTIR spectra at wavenumbers around 3650 $\mathrm{cm}^{-1}$ which corresponds to the $\mathrm{OH}$ group attached to EFAl species [21]. It is shown in Fig. 1(a) that the band around $3650 \mathrm{~cm}^{-1} \mathrm{can}$ be seen in the HMOR and after acid treatment. The wavenumber corresponds to the EFAl listed in Table 2.

The XRD patterns of the acid-treated mordenites were found to be almost identical (Fig. 2). However, the peak intensities slightly decreased which correspond to the crystallinity of the acid-treated mordenites. The crystallinity of the acid-treated mordenites changed from $100 \%$ to $68 \%, 74 \%$ and $88 \%$ for acid-treatment using acetic acid $6 \mathrm{M}$ (Fig. 2(c)), $9 \mathrm{M}$ (Fig. 2(d)) and $12 \mathrm{M}$ (Fig. 2(e)) respectively. It clearly shows that acetic acid

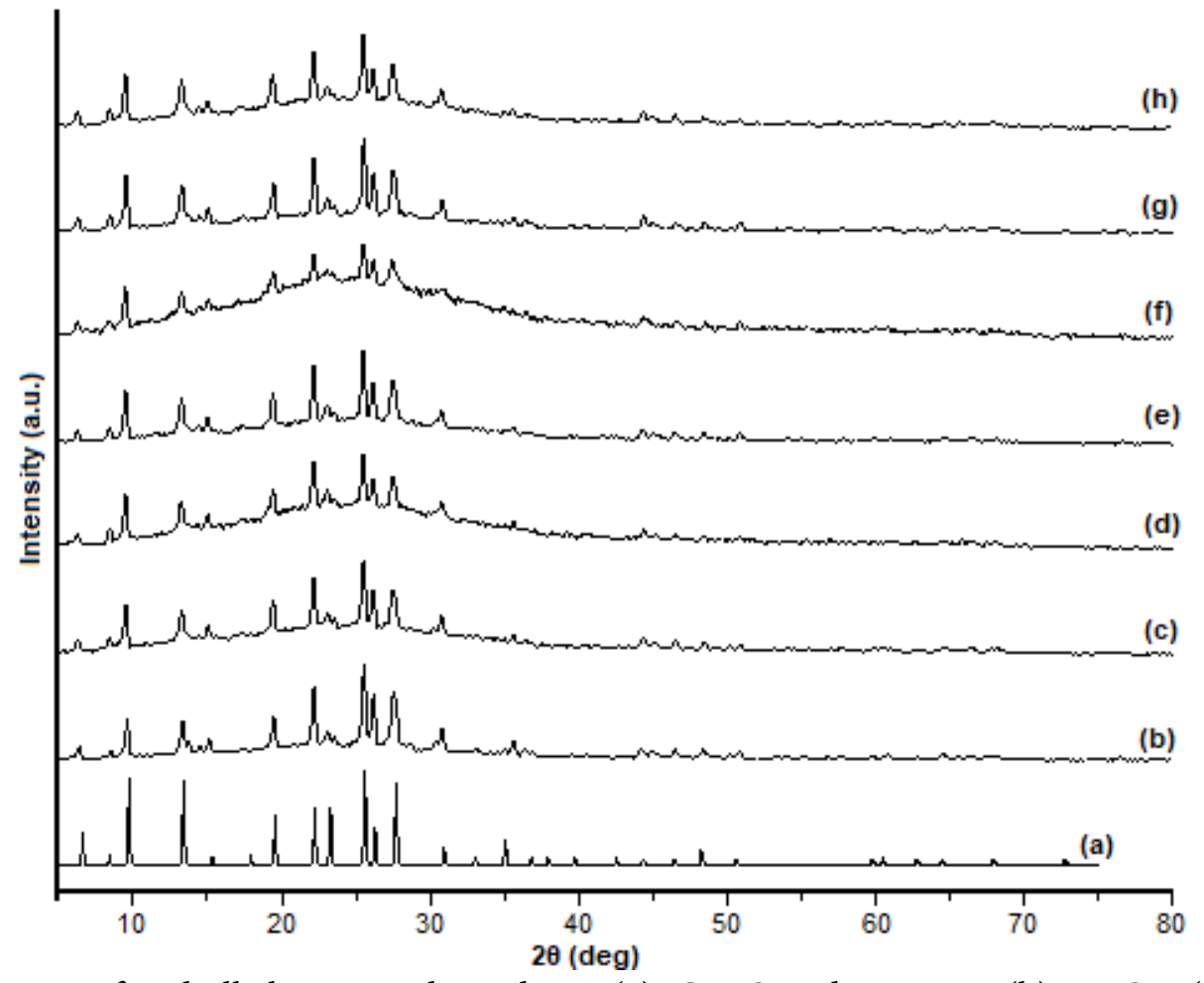

Fig 2. The diffractogram of acid-alkaline treated mordenite (a) JCPDS card 011-0155, (b) HMOR, (c) HMOR(6-9), (d) HMOR(9-9), (e) HMOR(12-9), (f) DHMOR(6-9), (g) DHMOR(9-9) and (h) DHMOR(12-9) 
$12 \mathrm{M}$ does not cause more damage than acetic acid $9 \mathrm{M}$. It can be suggested that acetic acid $12 \mathrm{M}$ removed the $\mathrm{Al}$ atoms from the mordenite framework, hence the EFAl was not completely formed during the acid treatment process. The EFAl species contributes to the amorphous nature of zeolites hence it can decrease the crystallinity of zeolites.

The uncompleted formation of EFAl on the mordenite framework is also supported by the $\mathrm{Si} / \mathrm{Al}$ ratio and the acidity of mordenite after acid treatment (Table 1). Table 1 shows that the acidity of $\operatorname{HMOR}(12-9)$ is the lowest for acid-treated mordenite. However, the $\mathrm{Si} / \mathrm{Al}$ ratio is not the highest. This indicates that EFAL in acidtreated mordenite using $12 \mathrm{M}$ of acetic acid is not completely formed during the acid treatment. When the acetic acid concentration is raised, it is expected that the $\mathrm{Si} / \mathrm{Al}$ ratio will increase. However the result shows that the $\mathrm{Si} / \mathrm{Al}$ ratio cannot exceed 25 (Table 1). The possible explanation for this is that a large number of aluminum atoms were extracted from the mordenite framework causing the framework to collapse (Fig. 2(c-e)). Hence, the silicon atoms were also removed from the mordenite framework and resulted in the lowering of the $\mathrm{Si} / \mathrm{Al}$ ratio.

\section{Acid-alkaline treated mordenite}

Alkaline treatment of zeolites cause the removal of Si sites on the mordenite framework. This process is well known as desilication. It can lead to the decrease of the $\mathrm{Si} / \mathrm{Al}$ molar ratio of mordenite. Zeolite framework contains more silicon than aluminum atom. Hence it would be easy to create mesopores upon alkaline treatment. However, it is reported that there is an optimal Si/Al ratio to create the mesoporosity of zeolite after alkaline treatment [15]. Above the optimum ratio, the $\mathrm{Al}$ atoms prevented the removal of $\mathrm{Si}$ from mordenite. This resulted in the limitation of mesopore formation. The optimal Si/Al ratio was 25 . When the $\mathrm{Si} / \mathrm{Al}$ molar ratio $>25$, the alkaline treatment caused a decrease in the Si/Al molar ratio (as seen in the case of the alkaline treatment of $\operatorname{HMOR}(6-9))$. However, when the Si/Al molar ratio $<25$, the Si/Al molar ratio increased after alkaline treatment (as seen in the case of the alkaline treatment of HMOR(12-9)). When $\operatorname{HMOR}(9-9)(\mathrm{Si} / \mathrm{Al}=19.08)$ was treated with alkaline, the $\mathrm{Si} / \mathrm{Al}$ molar ratio decreased. This is due to the removal of EFAl or maybe further dealumination that occurred on the mordenite framework, that caused the decrease of $\mathrm{Al}$ content on DHMOR(9-9).

We can see that the alkaline treatment of HMOR(6-9) decreased the crystallinity of mordenite down to $65 \%$. However, the characteristic peak of HMOR still appeared on the XRD pattern of DHMOR(6-9). When HMOR(9-9) was treated with sodium hydroxide, there was no significant change in the diffractogram of the mordenite (Fig. 2(d) and 2(g)). The crystallinity of HMOR(9-9) increased after alkaline treatment (DHMOR(9-9)) from 74 to 97\%. This indicates that the EFAl was removed from $\operatorname{HMOR}(9-9)$. However, the removal of Si atoms is more likely to occur than the removal of EFAl. This is supported by the Si/Al molar ratio and the acidity of DHMOR(9-9) (Table 1).

The increase of mordenite crystallinity after alkaline treatment also occurred on the DHMOR(12-9). The crystallinity of HMOR(12-9) was $88 \%$. After alkaline treatment, the crystallinity increased up to $93 \%$ (DHMOR(12-9)). This shows that the existence of EFAl or $\mathrm{Al}$ atoms prevents the removal of silicon atoms from HMOR(12-9). This result is in good agreement with the previous work of Shilagi et al. [15]. This result is also supported by the $\mathrm{Si} / \mathrm{Al}$ molar ratio of $\mathrm{HMOR}(12-9)$ after the alkaline treatment. There was an increase in the $\mathrm{Si} / \mathrm{Al}$ molar ratio (Table 1), which indicates that there was the removal of $\mathrm{Al}$ atoms either in the mordenite framework or EFAl. This result is also supported by the acidity of DHMOR(12-9).

\section{$\mathbf{N}_{2}$ Adsorption-Desorption}

Fig. 3 depicts the adsorption-desorption isotherm curve of mordenite. In general, the hysteresis loop of adsorption-desorption isotherm curve should close. However in Fig. 3, it can be seen that the hysteresis loop does not close. Usually, the loop that does not close is well known as low-pressure hysteresis loop. The lowpressure hysteresis loop could occur because of the swelling of the adsorbent during the adsorption process or when there is a chemisorption process together with physical adsorption [22]. However, in this case, the loop that does not close is not because of the low-pressure hysteresis loop. In the low-pressure hysteresis loop, in the 


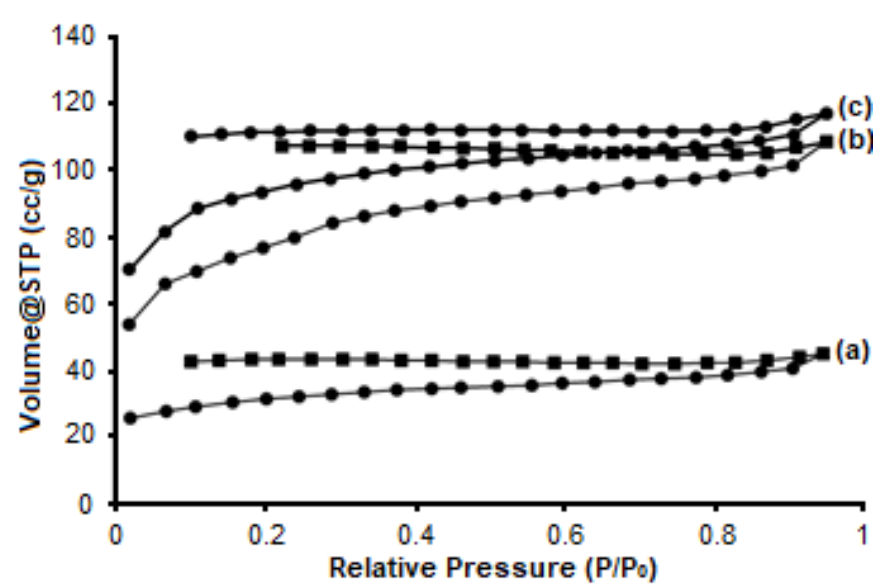

Fig 3. $\mathrm{N}_{2}$ Adsorption-desorption of (a) HMOR, (b) $\operatorname{HMOR}(6-9)$, and (c) DHMOR(6-9)

desorption process, the amount of adsorbate decreases as the relative pressure decreases. In this case, as the relative pressure decreases, the amount of the adsorbate increases. This shows that the desorption process releases more gases than the amount of gases in the adsorption process. This can be due to the incomplete degassing process [23].

Mordenite is well known as a porous material. Acid and Alkaline treatment would change the porosity of mordenite. Table 3 shows the pore characteristic of mordenite before and after the treatments. It can be seen that after acid and alkaline treatment, the BET surface area increased. This increase indicates the removal of $\mathrm{Al}$ atoms and $\mathrm{Si}$ atoms from the mordenite framework. The acid treatment removed $\mathrm{Al}$ atoms from the mordenite and rose the uniformity of the $\mathrm{Si}$ atoms in the mordenite. Zeolites with high $\mathrm{Si} / \mathrm{Al}$ ratio would have higher surface area than zeolites with low Si/Al ratio [24]. In accordance to Stefanidis et al., it was also reported that acid treatment of mordenite caused the increase of pore volume [14]. It was also reported that the combination of acid and alkaline treatment of mordenite caused the increase of surface area [25].

\section{The Catalytic Activity of Treated Mordenite}

Based on Table 4, it can be seen that a catalyst can increase the liquid fraction on the hydrotreatment product. The liquid fraction of HMOR(6-9) was lower than HMOR. Even though the specific surface area of HMOR(6-9) was higher than HMOR, the acidity of HMOR(6-9) was lower than that of HMOR. This result is in good agreement with Boveri et al. [13]. Boveri reported that mordenite after acid treatment showed less catalytic activity due to the elimination of the acid sites [13]. In the case of DHMOR(6-9), the result shows that DHMOR(6-9) had the highest liquid fraction of hydrotreatment product among all of the catalysts. Although the acidity of DHMOR(6-9) was lower than HMOR(6-9) and HMOR, the high specific surface area

Table 3. The pore characteristic of parent mordenite, acid-treated and acid-alkaline treated mordenite

\begin{tabular}{lrrr}
\hline \multirow{2}{*}{ Parameter } & \multicolumn{3}{c}{ Sample } \\
\cline { 2 - 4 } & HMOR & $\begin{array}{c}\text { HMOR } \\
(6-9)\end{array}$ & $\begin{array}{c}\text { DHMOR } \\
(6-9)\end{array}$ \\
\hline Average pore size $(\mathrm{nm})$ & 2.72 & 2.56 & 2.37 \\
Surface area $\left(\mathrm{m}^{2} \mathrm{~g}^{-1}\right)^{\mathrm{a}}$ & 102.31 & 262.07 & 306.14 \\
Total pore volume $\left(\mathrm{mL} \mathrm{g}^{-1}\right)^{\mathrm{b}}$ & 0.07 & 0.17 & 0.18 \\
\hline
\end{tabular}

Note: ${ }^{\text {BBET }}$ surface area determined using BET method

${ }^{b}$ Pore volume determined at $\mathrm{P} / \mathrm{P}_{0}=0.95$

Table 4. The distribution of hydrotreatment product

\begin{tabular}{lcccc}
\hline \multirow{2}{*}{ Catalyst } & \multirow{2}{*}{$\begin{array}{c}\text { Surface Area } \\
\left(\mathrm{m}^{2} \mathrm{~g}^{-1}\right)\end{array}$} & $\begin{array}{c}\text { Acidity } \\
\left(\mathrm{mmol} \mathrm{g}^{-1}\right)\end{array}$ & $\begin{array}{c}\text { Liquid Fraction } \\
(\text { wt.\% })\end{array}$ & $\begin{array}{c}\text { Gas Fraction } \\
(\text { wt.\% })\end{array}$ \\
\hline Thermal & - & - & 47.08 & 52.92 \\
HMOR & 102.31 & 25.88 & 74.40 & 25.60 \\
HMOR(6-9) & 262.07 & 16.59 & 66.66 & 33.16 \\
DHMOR(6-9) & 306.14 & 12.03 & 81.00 & 19.00 \\
\hline
\end{tabular}


of DHMOR(6-9) (Table 4) caused the liquid product to be improved. It clearly shows that the activity of the catalyst toward hydrotreatment was affected by the acidity and the surface area of the catalyst.

\section{- CONCLUSION}

Acetic acid as a weak acid can be applied for acid treatment of mordenite which is proven by the increase of $\mathrm{Si} / \mathrm{Al}$ ratio. The optimum condition for acid treatment of mordenite using acetic acid is $9 \mathrm{~h}$ using $6 \mathrm{M}$ of acetic acid under reflux method. On the other hand, alkaline treatment can be carried out at room to temperature, using a low concentration of $\mathrm{NaOH}$. The acid-alkaline treatment was able increase the surface area of mordenite and also increase the catalytic activity upon hydrotreatment of biomass-derived bio-oil.

\section{- ACKNOWLEDGMENTS}

This research was conducted under the research grant of PTUPT 2020 Universitas Gadjah Mada (Contract No.: 2876/UN1.DITLIT/DIT-LIT/PT/2020). Therefore, the authors would like to thank The Ministry of Research, Technology and Higher Education, the Republic of Indonesia for the financial support.

\section{- REFERENCES}

[1] Paixão, V., Carvalho, A.P., Rocha, J., Fernandes, A., and Martins, A., 2010, Modification of MOR by desilication treatments: Structural, textural and acidic characterization, Microporous Mesoporous Mater., 131 (1-3), 350-357.

[2] Huang, S., Liu, X., Yu, L., Miao, S., Liu, Z., Zhang, S., and Xie, S., 2014, Preparation of hierarchical mordenite zeolites by sequential steaming-acid leaching-alkaline treatment, Microporous Mesoporous Mater., 191, 18-26.

[3] Groen, J.C., Sano, T., Moulijn, J.A., and PérezRamírez, J., 2007, Alkaline-mediated mesoporous mordenite zeolites for acid-catalyzed conversions, $J$. Catal., 251 (1), 21-27.

[4] Pastvova, J., Kaucky, D., Moravkova, J., Rathousky, J., Sklenak, S., Vorokhta, M., Brabec, L., Pilar, R., Jakubec, I., Tabor, E., Klein, P., and Sazama, P., 2017, Effect of enhanced accessibility of acid sites in micromesoporous mordenite zeolites on hydroisomerization of $n$-hexane, ACS Catal., 7 (9), 5781-5795.

[5] Chaouati, N., Soualah, A., Hussein, I., Comparot, J.D., and Pinard, L., 2016, Formation of weak and strong Brønsted acid sites during alkaline treatment on MOR zeolite, Appl. Catal., A, 526, 95-104.

[6] Chen, C.Y., Ouyang, X., Zones, S.I., Banach, S.A., Elomari, S.A., Davis, T.M., and Ojo, A.F., 2012, Characterization of shape selective properties of zeolites via hydroisomerization of $n$-hexane, Microporous Mesoporous Mater., 164, 71-81.

[7] Baran, R., Millot, Y., Onfroy, T., Krafft, J.M., and Dzwigaj, S., 2012, Influence of the nitric acid treatment on $\mathrm{Al}$ removal, framework composition and acidity of BEA zeolite investigated by XRD, FTIR and NMR, Microporous Mesoporous Mater., $163,122-130$.

[8] Chung, K.W., 2008, Dealumination of mordenites with acetic acid and their catalytic activity in the alkylation of cumene, Microporous Mesoporous Mater., 11 (1-3), 544-550.

[9] Yusniyanti, F., 2018, Acid-alkaline treatment of mordenite as $\mathrm{MoO}_{3}$ support and its catalytic activity on the hydrotreatment of cellulose-derived bio-oil, Thesis, Department of Chemistry, Universitas Gadjah Mada, Yogyakarta.

[10] Ong, L.H., Dömök, M., Olindo, R., van Veen, A.C., and Lercher, J.A., 2012, Dealumination of HZSM-5 via steam-treatment, Microporous Mesoporous Mater., 164, 9-20.

[11] Verboekend, D., Vilé, G., and Pérez-Ramírez, J., 2012, Hierarchical Y and USY zeolites designed by post-synthetic strategies, Adv. Funct. Mater., 22 (5), 916-928.

[12] Ahmed, M.H.M., Muraza, O., Yoshioka, M., and Yokoi, T., 2017, Effect of multi-step desilication and dealumination treatments on the performance of hierarchical EU-1 zeolite for converting methanol to olefins, Microporous Mesoporous Mater., 241, 79-88.

[13] Boveri, M., Márquez-Álvarez, C., Laborde, M.Á., and Sastre, E., 2006, Steam and acid dealumination 
of mordenite Characterization and influence on the catalytic performance in linear alkylbenzene synthesis, Catal. Today, 114 (2-3), 217-225.

[14] Stefanidis, S., Kalogiannis, K., Iliopoulou, E.F., Lappas, A.A., Triguero, J.M., Navarro, M.T., Chica, A., and Rey, F., 2013, Mesopore-modified mordenites as catalysts for catalytic pyrolysis of biomass and cracking of vacuum gasoil processes, Green Chem., 15 (6), 1647-1658.

[15] Silaghi, M.C., Chizallet, C., and Raybaud, P., 2014, Challenges on molecular aspects of dealumination and desilication of zeolites, Microporous Mesoporous Mater., 191, 82-96.

[16] Almutairi, S.M.T., Mezari, B., Filonenko, G.A., Magusin, P.C.M.M., Rigutto, M.S., Pidko, E.A., and Hensen, E.J.M., 2013, Influence of extraframework aluminum on the Brønsted acidity and catalytic reactivity of faujasite zeolite, ChemCatChem, 5, 452466.

[17] Li, J., Li, X., Zhou, G., Wang, W., Wang, C., Komarneni, S., and Wang, Y., 2014, Catalytic fast pyrolysis of biomass with mesoporous ZSM-5 zeolites prepared by desilication with $\mathrm{NaOH}$ solutions, Appl. Catal., A, 470, 115-122.

[18] Bertrand-Drira, C., Cheng, X., Cacciaguerra, T., Trens, P., Melinte, G., Ersen, O., Minoux, D., Finiels, A., Fajula, F., and Gerardin, C., 2014, Mesoporous mordenites obtained by desilication: Mechanistic considerations and evaluation in catalytic oligomerization of pentene, Microporous Mesoporous Mater., 213, 142-149.

[19] Gackowski, M., Tarach, K., Kuterasiński, Ł.,
Podobiński, J., Jarczewski, S., Kuśtrowski, P., and Datka, J., 2018, Hierarchical zeolites Y obtained by desilication: Porosity, acidity and catalytic properties, Microporous Mesoporous Mater., 263, 282-288.

[20] Sandoval-Díaz, L.-E., González-Amaya, J.-A., and Trujillo, C.-A., 2015, General aspects of zeolite acidity characterization, Microporous Mesoporous Mater., 215, 229-243.

[21] Agudelo, J.L., Hensen, E.J.M., Giraldo, S.A., and Hoyos, L.J., 2015, Influence of steam-calcination and acid leaching treatment on the VGO hydrocracking performance of faujasite zeolite, Fuel Process. Technol., 133, 89-96.

[22] Kruk, M., and Jaroniec, M., 2001, Gas adsorption characterization of ordered organic-inorganic nanocomposite materials, Chem. Mater., 13 (10), 3169-3183.

[23] Silvestre-Albero, A.M., Juárez-Galán, J.M., Silvestre-Albero, J., and Rodríguez-Reinoso, F., 2012, Low-pressure hysteresis in adsorption: An artifact?, J. Phys. Chem. C, 116 (31), 16652-16655.

[24] Vu, X.H., Eckelt, R., Armbruster, U., and Martin, A., 2014, High-temperature synthesis of ordered mesoporous aluminosilicates from ZSM-5 nanoseeds with improved acidic properties, Nanomaterials, 4 (3), 712-725.

[25] Góra-Marek, K., Tarach, K., Tekla, J., Olejniczak, Z., Kustrowski, P., Liu, L., Martinez-Triguero, J., and Rey, F., 2014, Hierarchical mordenite dedicated to the fluid catalytic cracking process: Catalytic performance regarding textural and acidic properties, J. Phys. Chem. C, 118 (48), 28043-28054. 